\title{
Effects of Water Droplets on the Numerical Simulation of a Complete Gas Turbine
}

\author{
G.K. Dayyabu ${ }^{1,2, a^{*}}$, Q. Zheng ${ }^{1, b}$, H .Zhang ${ }^{1, \mathrm{c}}$, L. Sun ${ }^{1, \mathrm{~d}}$ \\ ${ }^{1,2}$ College of Power and Energy, Harbin Engineering University, China \\ ${ }^{2}$ Department of Mechanical Engineering, Hassan Usman Katsina Polytechnic, 820001 Katsina, Nigeria \\ Corresponding author: ${ }^{\mathrm{a}}$ nagari2010@gmail.com
}

Received 25 April 2017, Accepted 08 February 2018

\begin{abstract}
Numerical simulation of a complete gas turbine engine working with inlet wet injection has been evaluated using computational fluid dynamic (CFD), the effects of water droplet and injection rate on the compressor operation, engine combustion and the turbine were studied. The results obtained in contrast with dry compression unveil that, with minimum amount of water droplet and high water injection rate $(0.5 \%-3.0 \%)$ there is potential influence on the engine performance, it boost the amount of inlet mass flow rate, raises compression and expansion pressure ratio, uplift engine thrust and thermal efficiency through absorption of heat and radiation intensity emission, decreases the relative specific fuel consumption, combustion and turbine outlet temperature and cuts down the amount of NOx production.
\end{abstract}

\section{Keywords: Wet compression; gas turbine; water injection rate; NOx production.}

\section{Introduction}

Numerical simulation and experimental study research of the exhaust gas injection of a gas turbine has been done with propose of additional diversion bell mouth to the mixing section entrance. The experiments validate the numerical simulation results, and the tally situation is good [1]. In the last few decades, the advent of new and more stringent regulations on gas emission for stationary power systems ratified, the EPA promulgated revised new source performance standards (NSPS) for stationary combustion turbines applicable to stationary combustion turbines[2]. Gas turbines based on dry low Nox (DLN) burners of various manufacturers are now demonstrating $\mathrm{NOx}$ and $\mathrm{CO}$ levels below $10 \mathrm{ppm}[3]$. In many applications the old generation gas turbines, still based on conventional diffusion flame burners, are run with various unconventional fuels not fully compatible with modern lean-premix flame mode[4]. The new design improves the performance by changing transitional form of nozzle and its angular size. Meanwhile, the performance of the design has been predicted and the structure has been optimized by CFD method [5].

The effort to establish allowable levels of engine exhaust pollutants was begun by the United States Environmental Protection Agency, EPA. Numerous studies of ambient air quality in and around various airports were conducted[6]. Effects on the thermodynamic properties were thoroughly analyzed for different parameters such as compression speeds and overspray[7]. Any possible improvements of the performance of the gas turbine engines would help to minimize the worlds annual fossil fuel consumption and hence the emissions of the adverse greenhouse gasses[8]. Evaluation and measure of the appropriate parameters that describe the engine modes during changes of the exhaust nozzle diameter were studied, investigation the adaption of different performance maps of centrifugal compressors driven by dual-shaft gas turbines during operation was carried out, estimation of compressor, gas turbine and combined efficiency are considered [9]. Economic analysis of heavy duty industrial gas turbine plant has been investigated using a specified model[10]. The tip leakage vortex in the blade passage becomes closer to the blade suction surface, resulting in an increase of the heat transfer coefficient [11]. An analogy between different cooling systems was set up on computer simulation model, performance characteristic were analyzed and the results show evaporation is more economically than cooling coil system in refrigeration unit [12]. In modelling of combustor, it conclude that wet cycle gas turbines possess higher number of full load equivalent operating hours and can fetch higher investment payback with minimum limitation to their overall environmental performance [13]. Similarly, one of the most frequent solutions to the performance of an industrial gas turbine can be using the humidified gas turbines, a phenomenal by which water or steam is sprayed at different positions on the system to boost out the power[14]. In the face of the constant consumption of the earth's energy, increasing the utilization rate of the fuel, increasing the efficiency of the engine has become an important goal for the scientific research workers in the gas turbine industry $[15,16]$. Their results show that, water injection is not only a technique to improved thermodynamics performance, but also a method to stabilize the compression system when it approaches stall $[17,18]$.

Among the motives of wet compression is moving towards isothermal compression from adiabatic compression [19]. Details analysis on evaluation stage-by-stage compressor performance with water injection is by using the stage-stacking method $[20,21]$. The heat transfer mostly rely on the geometry of the fin like length, thickness, cross sectional area, width, spacing between the fins [22]. More than 1000 gas turbines with inlet cooling presently installed [23]. For each $5^{\circ} \mathrm{C}$ decrease of inlet air temperature, net 
output power increases around 5-10\% [24].

Details research studies point out some major differences such as increased specific work and overall compressor power when compared to the work of the other researchers [25]. In axial flow analysis on industrial gas turbine, imprecise axial gap and tip clearance are two major sources of inefficiency [26].

Water droplets were injected at the inlet of the axial compressor, assuming uniformly distributed streams along the inlet surface [27]. Climatic environment and variation of load cause changes in the operation of gas turbine components, specifically fuel consumption [28]. A change in flow angle at the cascade outlet is observed depending on water-load and droplet-size in the inlet, during investigation on the influence of water droplets in compressor cascades [29]. Relationship between combustor operating conditions and thermal NOx production investigated. NOx increases strongly with fuel-to-air ratio or with firing temperature[30]. Results of injection of water particles into a compressor cascade using a wind tunnel, show reduction in air velocity around compressor airfoils due to the impact of large, high inertia droplets on the momentum of the airflow, the change appeared to be function of the injected water-droplet size and mass flow[31]. From experimental point of view different axial locations of fuel nozzle in the swirled on combustor have great influence on the combustor temperature[32]. A comprehensive collation of spatial distribution of emissions from automobiles and industrial activities in Asia pacific shows high emission of sox in inland grid of china[33]. A collection of slides comprising, gas turbine systems, gas engine systems, high hydrogen project, rig instrumentation, pressure transducers and K-type thermocouples were analyzed for the combined cycle [34]. Injection of alcohols in open-cycle gas turbines during the compression process is considered for intercooling, cases of useful pressure and temperature variation are accounted[35]. Evaluation and measure of the appropriate parameters that describe the engine modes during changes of the exhaust nozzle diameter were studied for turbo jet engines [36].

\section{Problem Statement}

From the literatures reviewed many of the authors have contributed toward the success of the wet compression techniques on the performance of the compressor of an industrial gas turbine, but not much has been done to simulate the complete gas turbine with wet compression, to analyze its performance influence on the entire system and sub-components of the system. In the present work, an effort to augment the literatures on the thermo-physics of wet compression effect on complete engine has been presented, a numerical simulation of the complete gas turbine was carried out using computational fluid dynamic (CFD) software to evaluate the system performance with and without water droplets. Some of the components of the engine, include three stages compressor, direct flow annular combustor and an axial turbine.

Numerous simulation was carried out at various degree of water injection rate and amount of water droplet, the high inlet temperature of the gas was maintained at $42^{\circ} \mathrm{C}$ and relative humidity of $40 \%$. The present work has taken relative humidity into consideration at the boundary condition in contrast with previous work in reference [18] and uses different inlet temperature throughout the simulations.

\section{Gas Turbine Engine Configuration}

The engine configuration consists of three main components shown in Figure 1. Axial compressor of 3stages, annular combustor and one stage axial turbine. The compressor consists of multi-block structured grids of 579,348 elements, the turbine has 210,620 , while the combustor parts consist of 665,610 respectively. Simulation were performed under the steady condition for both dry and wet conditions and at different diameter of water droplets and different injection rate. Furthermore, Figure 2 shows pressure-volume $(\mathrm{P}-\mathrm{V})$ and temperature-entropy (T-S) diagrams of the full dry engine compression and wet compression processes, supposing uniform fuel ratio per unit mass of dry air, the amount of heat to be added per each unit mass of dry air and wet cycle on the area b-1-2-3-4-d is equal to the area a-2 $-3-4-c-d-a$. Heat rejected for wet compression cases $b-1-4-c-b$ is relatively smaller than dry cases b-1-4-d-b.

The Dry and wet compression work from the P-V diagram equal to the area 2-3 and 2-3 respectively. Whereas at any point along low pressure line of PV diagram and low temperature line of TS diagram have different volume and entropy respectively.

\subsection{Model and Governing Equations}

Moving from suction region of the compressor to the higher temperature section of combustor and turbine, thermodynamic properties of fluid flow are subject to diverse changes. In the present work, specific heat of the air and water droplets in gasses and liquids phases are expressed as fourth degree polynomial functions of temperature to enable an exact forecast of the energy and its preservation. Similarly, the latent heats of phase changes and heating value of fuel combustion can be acquired instantly from the result of the variables of thermodynamic properties [14].

The conventional $k-\varepsilon$ model is selected to reckon for the turbulence. Radiation/Gibbs model is chosen for the fluids in the combustion chamber and Monte Carlo model is used for the solid parts of the combustor [36]. For the combustion of fuels, a combined model of eddy dissipation model/finite rate is applied to determine the effectiveness of the rate of reaction and a two-step reaction mechanism is chosen, the fuel to air reaction is given as:

$\mathrm{C}_{12} \mathrm{H}_{23}+71 \mathrm{O}_{2} \rightarrow 48 \mathrm{CO}_{2}+46 \mathrm{H}_{2} \mathrm{O}$

Complete combustion in Eq. (1) does not actually occur and other products can include $\mathrm{CO}$ and unburnt fuel

$$
\begin{aligned}
& 100 \mathrm{C}_{12} \mathrm{H}_{23}+1175 \mathrm{O}_{2} \rightarrow 1200 \mathrm{CO}_{2}+1150 \mathrm{H}_{2} \mathrm{O} \\
& \mathrm{CO}+1 / 2 \mathrm{O}_{2} \rightarrow \mathrm{CO}_{2} \\
& \mathrm{~N}_{2}+\mathrm{O}_{2} \rightarrow 2 \mathrm{NO}
\end{aligned}
$$

Engine thrust is calculated through the below equation:

$$
F_{N}=\dot{m}_{g} c_{\text {out }}-\dot{m}_{g} c_{\text {in }}+\left(P_{\text {out }}-P_{\text {in }}\right) A_{\text {out }}
$$

Where $\dot{m}_{g} c_{\text {out }}-\dot{m}_{g} c_{\text {in }}$ the net momentum thrust, $P_{\text {out }}-P_{\text {in }}$ is the difference in pressure of inlet compressor and turbine outlet. $A_{\text {out }}$ is the area of turbine outlet section.

\subsection{Relationship of the Mass Flow Rate}

To achieve feasible and convergent solution during engine 
operation, there should be a balance between the mass flowrate of the fluids at inlet and outlet.

$\dot{m}_{f}+\dot{m}_{a}+\dot{m}_{w}=\dot{m}_{g}+K_{w} \dot{m}_{w}$

Where, $\dot{m}_{f}$ is the mass flow rate of the injected fuel, $\dot{m}_{a}$ is the mass flow rate of the air, $\dot{\mathrm{m}}_{\mathrm{w}}$ is the mass flow rate of injected water, $\dot{m}_{g}$ is the mass flowrate of turbine outlet gas and $K_{w}$ is the trap ratio of water.

\subsection{Boundary Condition}

The boundary condition for the engine simulation are provided in Table 1. The pressure is set at $101.3 \mathrm{Kpa}$, ambient temperature of $288.15 \mathrm{~K}$ and uniform distribution of total pressure, total temperature and flow direction were set at the compressor inlet boundary while, static pressure was prescribed at the exit of the turbine. Fuel injection at the rate of $7.50 \mathrm{~kg} / \mathrm{s}$ is used, the amount of the fuel is set relative to the inlet mass flow rate of the dry air.

Table 1. Parameters at Boundary condition.

\begin{tabular}{|c|c|c|}
\hline & Shaft speed (rpm) & 29500 \\
\hline $\begin{array}{l}\text { Compressor } \\
\text { inlet }\end{array}$ & $\begin{array}{l}\text { Total pressure }(\mathrm{kPa}) \\
\text { Total temperature }(\mathrm{K}) \\
\text { Rel. humidity }\end{array}$ & $\begin{array}{l}152,575 \\
340 \\
0.4\end{array}$ \\
\hline $\begin{array}{l}\text { Turbine } \\
\text { outlet }\end{array}$ & $\begin{array}{l}\text { Average static } \\
\text { pressure }(\mathrm{kPa})\end{array}$ & 162,120 \\
\hline $\begin{array}{l}\text { Water } \\
\text { injection }\end{array}$ & $\begin{array}{l}\text { Injecting rate per unit } \\
\text { mass of inlet dry air. } \\
\text { Droplet mean diameter } \\
(\mu \mathrm{m}) \\
\text { Velocity }(\mathrm{m} / \mathrm{s}) \\
\text { Temperature }(\mathrm{K})\end{array}$ & $\begin{array}{l}0,0.5 \%, 1 \% \\
2 \%, 3 \% . \\
5,10,15,20,30 \\
50 \\
315\end{array}$ \\
\hline $\begin{array}{l}\text { Fuel } \\
\text { injection }\end{array}$ & $\begin{array}{l}\text { Injecting rate per unit } \\
\text { mass of inlet dry air. } \\
\text { RR mean diameter }(\mu \mathrm{m}) \\
\text { Injecting velocity }(\mathrm{m} / \mathrm{s}) \\
\text { Temperature }(\mathrm{K})\end{array}$ & $\begin{array}{l}1.70 \% \\
20 \\
50 \\
15\end{array}$ \\
\hline
\end{tabular}

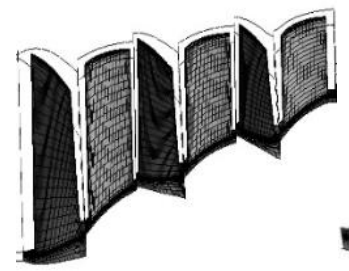

(a) Compressor grid

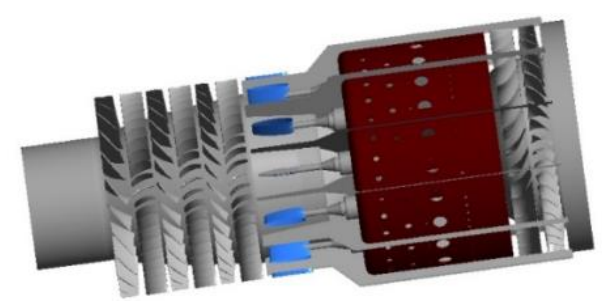

(c) Assembled turbine engine

Figure 1: Components grid and assembled complete turbine engine.
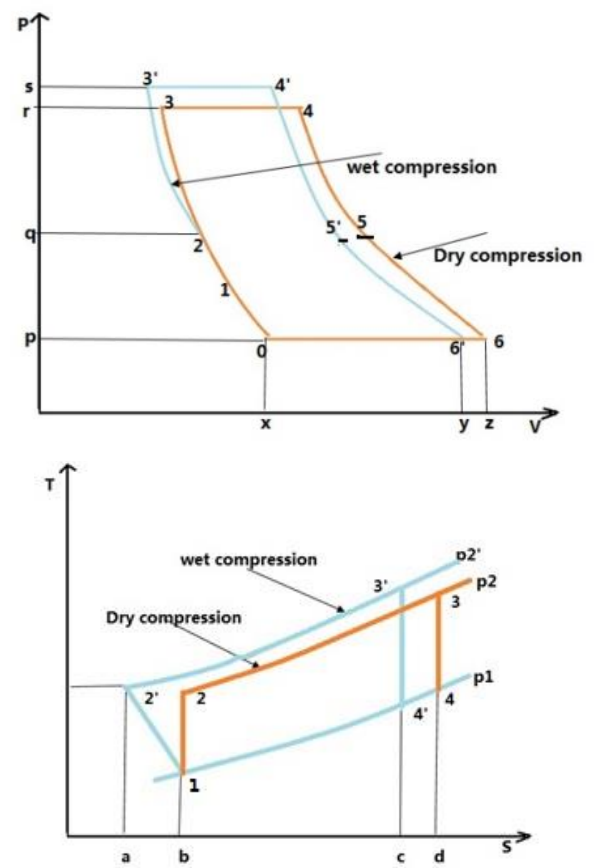

Figure 2: $P-V$ and T-S diagram of the engine.

\section{Discussion of Results}

To discuss the results from the simulation processes, some pictures of temperature and pressure contours along the compressor and turbine meridionals as well as the blades surfaces were captured at different microns and different water injection rate is presented below. Some graphs of specific fuel consumptions, efficiencies, particle diameters, the temperature and pressure were also plotted and discussed below.
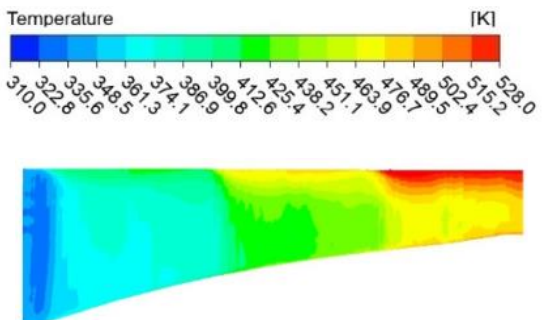

(a) Dry compression

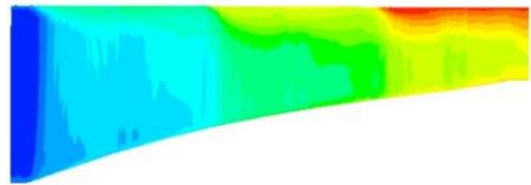

(b) 5 microns wet compression

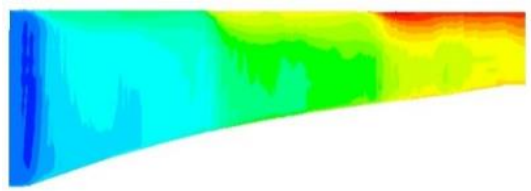

(c) 10 microns wet compression

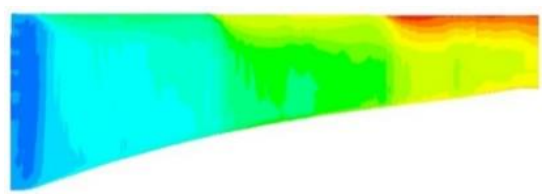

(d) 20 microns wet compression

Figure 3: Contours of temperature along 3 stage compressor meridionals. 
Keeping the inlet condition constant, computational analysis was carried out to predict the temperature contour along the meridional of three-stage compressor of gas turbine for both dry and wet compression. The temperature at the inlet reduces with wet compression by around $31 \mathrm{~K}$ and $22 \mathrm{~K}$ on case Figure $3 b$ and Figure $3 c$ with respect to case dry compression in Figure 3a. The temperature decline at the inlet tend to be lessens with increase in the amount of water droplets in micron. Temperature at the compressor meridional outlet drops also with wet compression, minimum amount of 5 microns gives reduction of the outlet temperature by an average of $11 \%$.

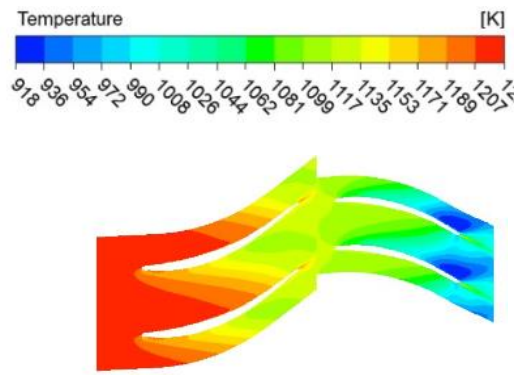

(a) Dry compression

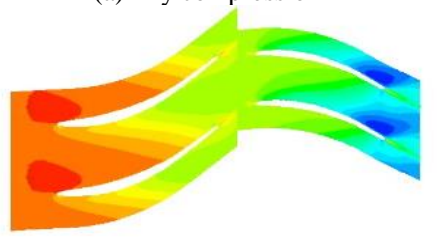

(b) 5 microns wet compression

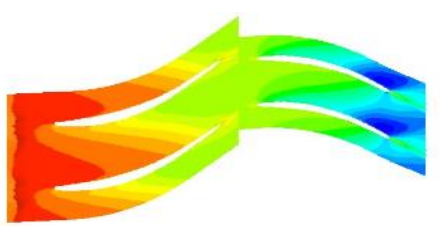

(c) 10 microns wet compression

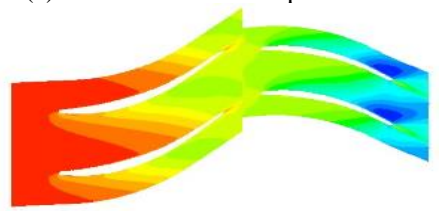

(d) 20 microns wet compression

Figure 4: Contours of temperature along the turbine meridional.

Turbine work is an integral part of temperature and pressure, if pressure ratio is boosted concurrently with reduction in temperature it means more work is to be done to the turbine. Wet compression has significantly reduced the turbine outlet temperature to an average of $26 \mathrm{~K}$ in the course of expansion process, the temperature reduction however, shrinks with increase in the amount of water droplet.

Water droplets injected in to the compressor inlet has characteristics influence on the performance of the compressor, among such parameters to measure its performance is mean particle diameter. Mean particle diameter of water droplets decreases along the axial of the compressor due to the effects of evaporation, residence time and phase changes during the compression, from the Figure 5 there is no remarkable change with variation of injection rate, but a revealing change is noticed when the amount of water droplet soared to 10 microns. Moreover, the particle diameter concentrates heavily on first stage rotor blades due to proximity to the nozzles position.

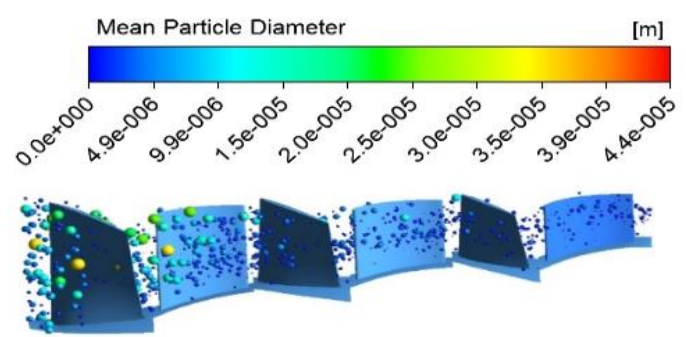

(a) 5 microns, $1 \%$

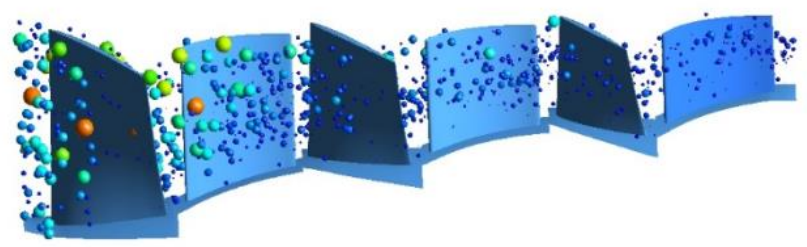

(b) 5 microns, $3 \%$

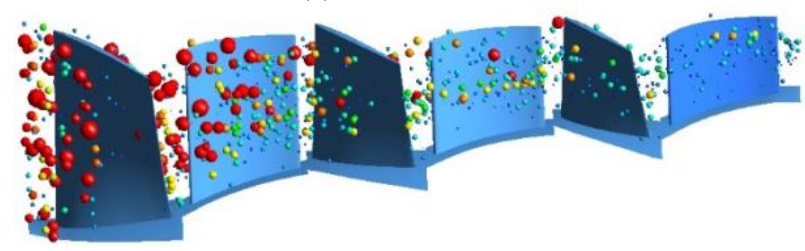

(c) 10 microns

Figure 5: Mean particle diameter of water droplet along 3 stages of the compressor.

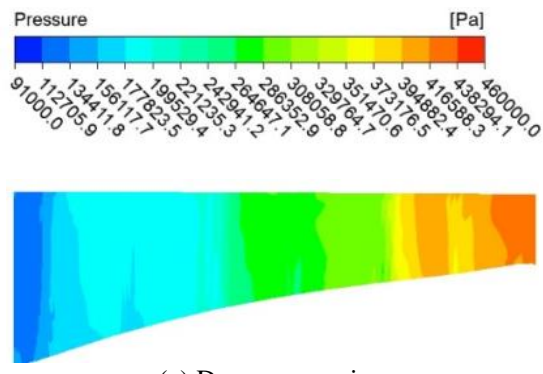

(a) Dry compression

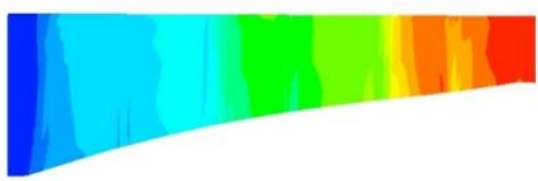

(b) 5 microns wet compression

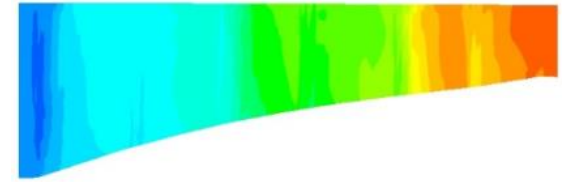

(c) 10 microns wet compression

Figure 6: contours of Pressure along the 3-stage compressor meridional.

Wet compression process possesses the ability to augments the compressor and turbine performance and also system efficiency by increasing the compression and turbine ratio.

Wet compression raises the compression pressure to an average of 7 percent, thus, elevates the compression pressure to around $450 \mathrm{kPa}$ against dry compression value of $400 \mathrm{kPa}$ at the exit. However, the pressure tends to lessen with increase in the amount of water droplets.

Consecutively, turbine expansion ratio was raised to about 5-6 percent, thereby elevating the turbine pressure to around $390 \mathrm{kPa}$ against the dry compression pressure of 365 $\mathrm{kPa}$. Higher pressure means more work to be carried out by both compressor and turbine. 


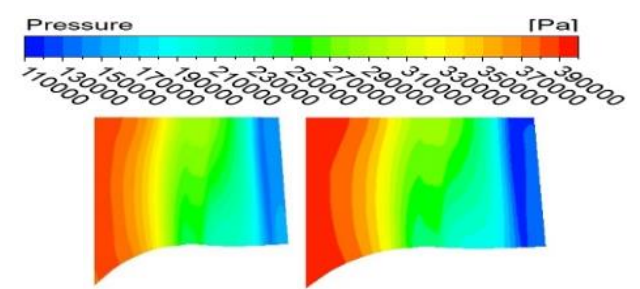

(a) Dry compression (a) 5 microns compression

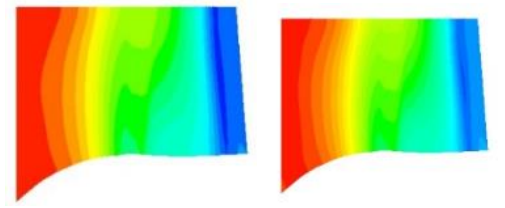

(b) 10 microns compression (d) 20 microns compression

Figure 7: Contours of pressure along the turbine Meridional.

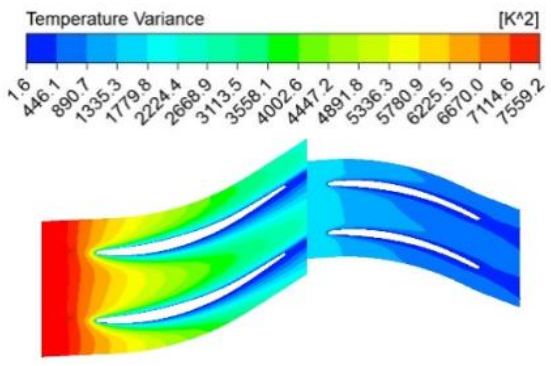

(a) Dry compression

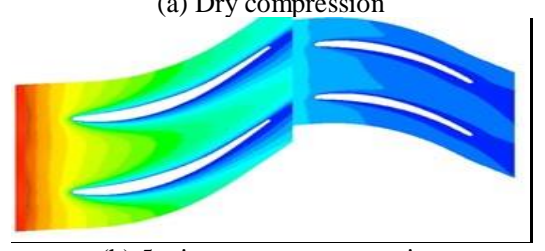

(b) 5 microns wet compression

Figure 8: Contours of temperature variance on the turbine blades.

Temperature variance is squarely a function of the absolutes temperature on the turbine blades, it depicts the actual behavior on the effect and variation of water droplet acting on the temperature blades, it trend is similar to the variation of the turbine contour of temperature. Water droplets reduces the temperature variance by 8.0 percent against the dry compression

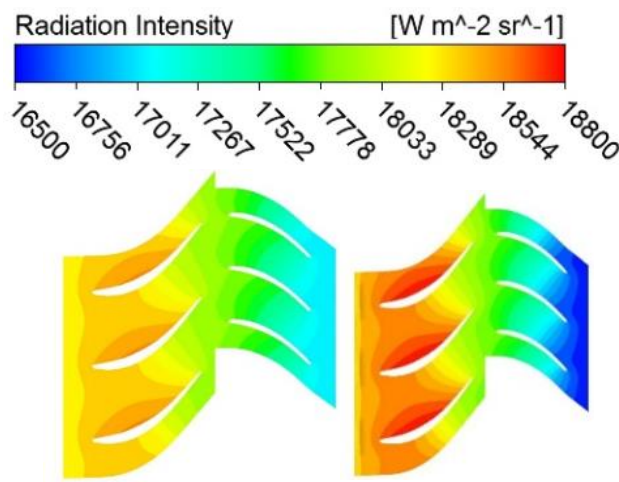

(a) Dry compression (b) 10 microns wet compression

Figure 9: Contours of radiation intensity on the turbine blades.
Water droplets causes an evaporation and convection of heat transfer on to the sucked air in the compressor, which affect the combustion work of the gas turbine.

Evaporation start to occur due to difference in vapor molar concentration between the bulk and droplet surface, evaporation and convectional flow of air causes the temperature to drops, which eventually shrinks the heat and radiation emission (reduction of heat and radiation means more thermal efficiency in the system), this phenomenon continuous in the expansion work of the turbine, radiation intensity on the rotor and stator blades of the turbine. With wet compression radiation intensity intensifies, for effective and efficient turbine work, heat and mass transfer radiation intensity must be kept within the required limit.

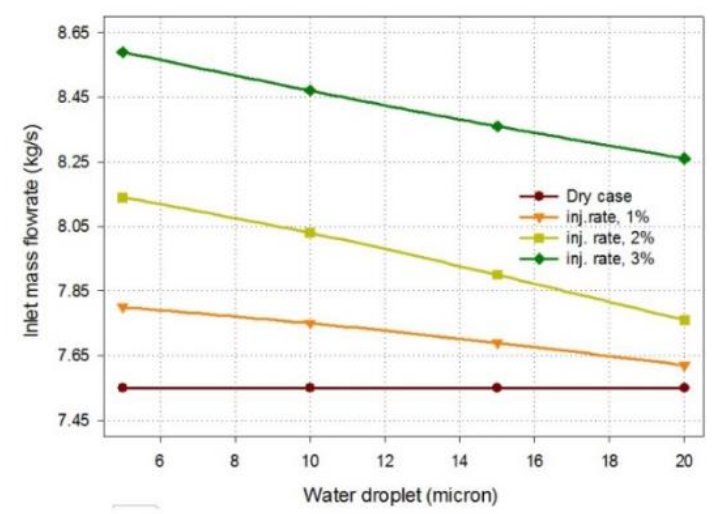

Figure 10: Engine inlet mass flow rate.

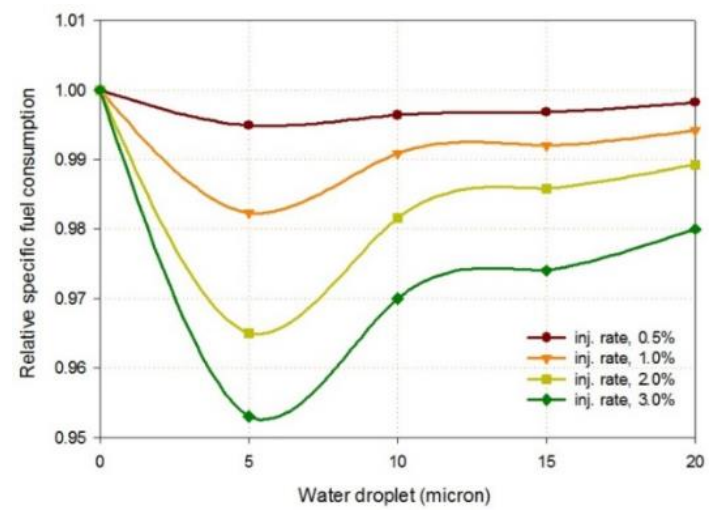

Figure 11: Relative specific fuel consumption of the engine ( $s f c / s f c$, dry ).

Figure 10 shows variation of inlet mass flow rate against water droplet at different water injection rate, the amount of inlet mass flow rates increases proportionately with injection rate and the smaller amount of water droplets provides the engine sufficient amount of air flowrate.

Figure 11 presents relative specific fuel consumption against water droplets at various injection rate. Water injection rate reduces the amount of relative specific fuel consumption appropriately, with water droplet of 5microns and 20 microns, $3.0 \%$ injection rate the relative specific fuel consumption drops by 5.10 percent and 2.02 percent respectively. The lower the amount of water droplet the better and more economical the fuel consumption might be. 


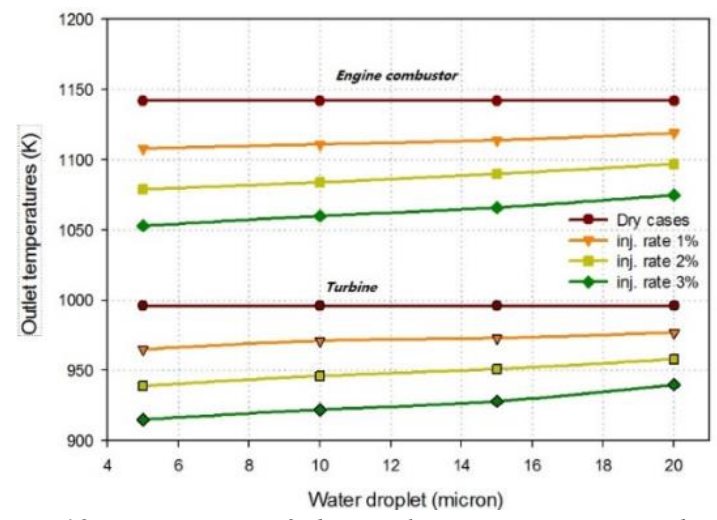

Figure 12: Variation of the outlet temperature with water injection rate.

A relationship between the outlet temperature of the combustion and turbine against water droplets at various injection rate is presented in Figure 12 dry combustion and turbine work outlet temperature were simulated at maximum outlet temperature of $1145 \mathrm{~K}$ and $995 \mathrm{~K}$ respectively. In both dry and wet compression of engine combustor and turbine work, the outlet temperature reduces with increase value of water injection rate, however there is relatively low influence with elevation of water droplets.

Engine combustion outlet temperature in Figure 12 when correlated to the dry case, drops from $1145 \mathrm{~K}$ to an average of $1070 \mathrm{~K}$ at 5 microns and $1100 \mathrm{~K}$ at 20 microns of water droplet. Subsequently, the turbine outlet temperature drops from $999 \mathrm{~K}$ to an average of $940 \mathrm{~K}$ at 5 microns and to an average of $955 \mathrm{~K}$ at 20 microns of water droplet.

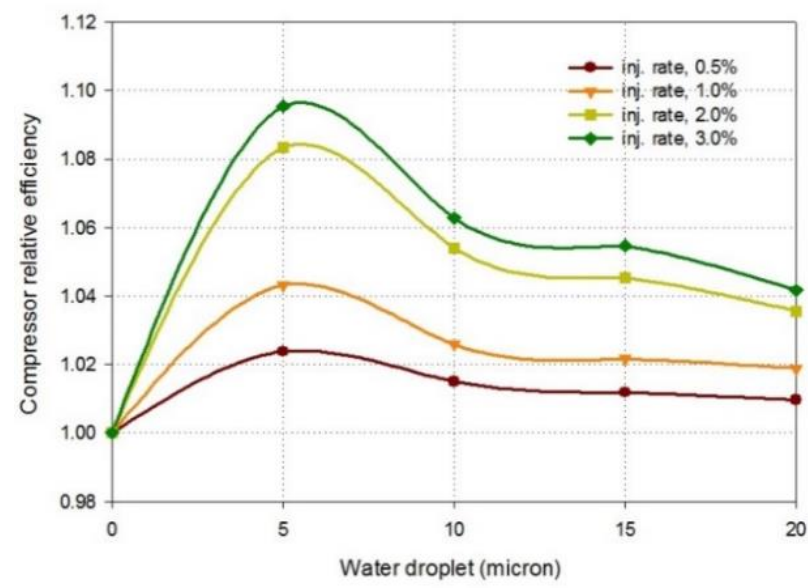

Figure 13: Variation of the compressor efficiency with water injection rate $\left(\eta_{c} / \eta_{c}\right.$, dry $)$.

Figure 13 shows the optimum compressor efficiency obtainable through the compression process. Water droplets increases the mass flow rate and reduces the temperature of the compression process, which significantly affect the efficiency of the compressor. Wet compression efficiencies divided by dry case efficiency were plotted against the water droplet at various injection rate. For injection rate of $0.5 \%$ to $2.0 \%$ the relative efficiency increases by 3.50 percent, 4.40 percent, 5.15 percent and 8.0 percent respectively. The percentage increase is at horizon when the water droplet is at 5 microns at all level of the injection rate.

Unlike the compressor which it efficiency augmented with water injection rate, the relative turbine efficiency presented in Figure 14 slightly decline with water injection rate. In general, the percentage decreases of the relative turbine efficiency for water droplets is less than or equal to 0.35 percent.

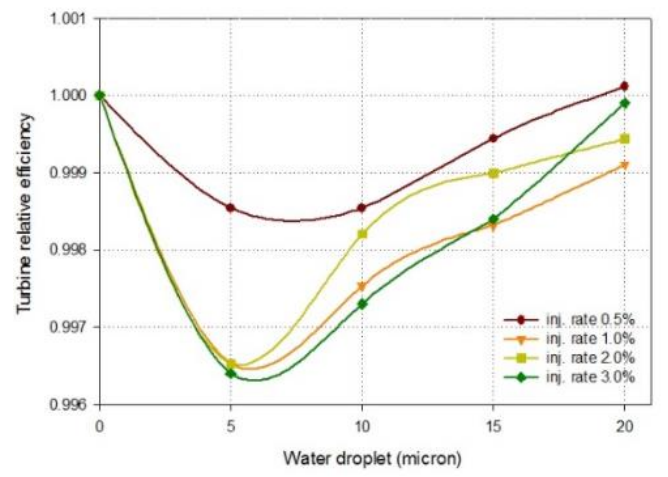

Figure 14: Variation of turbine efficiency $\left(\eta_{t} / \eta_{t},{ }_{\text {dry }}\right)$.

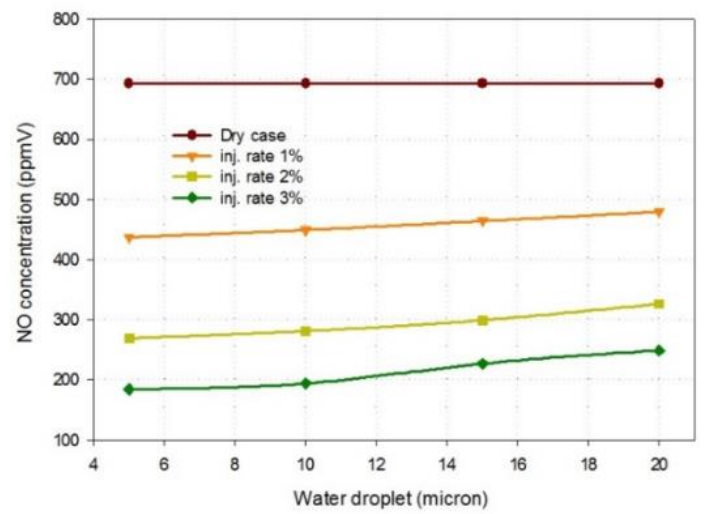

Figure 15: Variation of the amount of exhaust at different water injection rate.

To secure permissible minimum level of emissions from turbines and engines around the globe, environmental protection agency regulations for power stations and gas turbines are currently being reviewed every now and then. However, wet compression techniques are frequently used to cut down level of NOx emission as shown in the above Figure 15, the NOx level decreases with water injection rate from dry compression level of $700 \mathrm{ppm}$ to an average of $300 \mathrm{ppm}$. The NO reduces proportionally with water injection rate and its shows minimum value at 5micron, $3 \%$ injection rate.

\section{Conclusions}

Computational fluid dynamic of a complete gas turbine to ascertain its performance effects with and without wet compression has been carried out and the results were presented, wet compression brought cooling to the inlet air mass, thus reduces the inlet temperature and uplift the mass flow rate in to the turbine. Complete computational flow analysis allows us to view beyond the outlet temperature of the compressor, it rather allow to view other sub-components like combustor and turbine, which drastically changes with wet compression. The reduction of the components outlet temperature means more efficient to the system.

With account of relative humidity during the inlet condition, radiation intensity was physically detected and presented and the compression ratio were quite significant than in the previous work presented in reference [18].

Looking in to the graphs of the inlet mass flow rate, specific fuel consumption, components outlet temperature and NOx level, water injection rate plays a vital role in bringing down the duo levels. On the contrary in the efficiencies graphs amount of water droplets is dominants in 
state changes. However, with wet compression the engine operates economically with less specific fuel consumption, and the pressure ratio is raised while temperature reduction, which means heat rejection and radiation intensity is utilized as shown on Figure 2 and Figure 9 respectively. One important aspect of this research is that, it's environmentally friendly, and it cuts the level of NOx toward attaining allowable environmental protection agency [EPA] permissible pollution and exhaust level.

Conclusively, one of the setback observed during the numerical analysis is the slight decline in the turbine relative efficiency operates with small amount of water droplets even though it does well in raising the relative efficiency of the compressor.

\section{Acknowledgements}

The authors would like to acknowledged and appreciate the efforts of turbomachinery research group, Chinese government scholarship council and tertiary education trust fund (Tetfund) Nigeria, grant number HUKP/PS/S/01920/1/82.

\section{Nomenclature}

Symbols

$\begin{array}{cll}A_{\text {out }} & \text { Area of turbine outlet } & \mathrm{m}^{2} \\ F_{N} & \text { Engine thrust } & \mathrm{N} \\ C_{\text {in }} & \text { Speed of the gas at inlet } & \mathrm{m} / \mathrm{s} \\ C_{\text {out }} & \text { Speed of the gas at outlet } & \mathrm{m} / \mathrm{s} \\ K_{W} & \text { Trap ratio of water } & \\ m_{a} & \text { Mass flowrate of air } & \mathrm{Kg} / \mathrm{s} \\ \dot{m}_{f} & \text { Mass flowrate of fuel } & \mathrm{Kg} / \mathrm{s} \\ \dot{m}_{g} & \text { Mass flowrate of gas } & \mathrm{Kg} / \mathrm{s} \\ m_{w} & \text { Mass flowrate of water } & \mathrm{Kg} / \mathrm{s} \\ \dot{m}_{g} C_{\text {out }} & \text { Momentum outlet } & \mathrm{Ns} \\ \dot{m}_{g} C_{\text {in }} & \text { Momentum inlet } & \mathrm{Ns} \\ P_{\text {in }} & \text { Compressor inlet Pressure } & \mathrm{Pa} \\ P_{\text {out }} & \text { Turbine outlet pressure } & \mathrm{Pa}\end{array}$

\section{References}

[1] Z. Wang, T. Wang, T. Sun, and J. Han, "The Study on the Performance of the Gas Turbine Exhaust Gas Injection," in Power and Energy Engineering Conference (APPEEC), 2011 Asia-Pacific, Wuhan China, 2011, pp. 1-4. https://www.ieee-pes.org/appeec-2009

[2] E. P. Agency, "Standards of Performance for Stationary Gas Turbines, Proposed results," vol. / Vol. 77, No. 168 August 29 ,

2012 https://www.federalregister.gov/documents/2012/08/29 /2012-20524/standards-of-performance-for-stationarygas-turbines-standards-of-performance-for-stationary

[3] L. B. Davis and S. Black, "Dry Low NO x Combustion Systems for GE Heavy-Duty Gas Turbines," in POWERGEN-CONFERENCE-, California USA DEC 5-7, 1995, pp. 57-68.

[4] F. Bonzani and R. Maali, "Low BTU Fuels Operation in Heavy Duty Gas Turbines: Ansaldo Energia Experience," in ASME 2006 Power Conference, Atlanta ,Georgia May 2-4 2006, pp. 429-436.

[5] Z. Xun, W. Wu, and D. Han, "A new design and simulation of gas turbine exhaust ejector," in Fluid Machinery and Fluid Engineering, 2014 ISFMFE-6th International Symposium, Wuhan China Oct 22-25,
2014, pp. 1-4.

[6] R. E. Jones, "Gas Turbine Engine EmissionsProblems, Progress and Future," Progress in Energy and Combustion Science,elsevier, vol. 4, pp. 73-113, 1978.

[7] A. Mohan, P. K. Chidambaram, A. Suryan, and H. D. Kim, "Thermo-fluid dynamic analysis of wet compression process," Journal of Mechanical Science and Technology, vol. 30, pp. 5473-5483, 2016.

[8] D. Klein and C. Abeykoon, "Modelling of a turbojet gas turbine engine," in Internet Technologies and Applications (ITA), 2015, pp. 200-206. doi: 10.1109/ITechA.2015.7317395

[9] A. Cortinovis, M. Zovadelli, M. Mercangoz, D. Pareschi, A. De Marco, and S. Bittanti, "Online adaptation of performance maps for centrifugal gas compressors," in Control Conference (ECC), strasbourg,france, july 24,2014, pp. 1036-1041.

[10]X. Liang, Y. Xue, and Z. Li, "Techno-economic analysis of applying China's R0110 gas turbine in IGCC plants," in Materials for Renewable Energy \& Environment (ICMREE), 2011 International Conference shanghai China, 2011, pp. 1674-1677. ieeexplore.ieee.org/xpl/mostRecentIssue.jsp?punumber $=5784219$...IS...6

[11]F. Zhong, C. Zhou, H. Ma, and Q. Zhang, "Heat Transfer of Winglet Tips in a Transonic Turbine Cascade," Journal of Engineering for Gas Turbines and Power, vol. 139, p. 012605, 2017.

[12]Q. Jaber, J. Jaber, and M. Khawaldah, "Assessment of power augmentation from gas turbine power plants using different inlet air cooling systems," JJMIE, vol. 1, 2007.

[13]A. Andreini, T. Bacci, M. Insinna, L. Mazzei, and S. Salvadori, "Hybrid RANS-LES Modeling of the Aerothermal Field in an Annular Hot Streak Generator for the Study of Combustor-Turbine Interaction," Journal of Engineering for Gas Turbines and Power, vol. 139, p. 021508, 2017.

[14] S. W. Lee, S. U. Kim, and K. H. Kim, "Aerodynamic performance of winglets covering the tip gap inlet in a turbine cascade," International Journal of Heat and Fluid Flow, vol. 34, pp. 36-46, 2012.

[15] Q. Zheng, Y. Sun, S. Li, and Y. Wang, "Thermodynamic analyses of wet compression process in the compressor of gas turbine," in ASME Turbo Expo 2002: Power for Land, Sea, and Air, Amsterdam, Netherlands June 3-6 2002, pp. 487-496.

[16]Q. Zheng and M. Li, "Wet Compression System Stability Analysis: Part II-Simulations and Bifurcation Analysis," in ASME Turbo Expo 2004: Power for Land, Sea, and Air, Vienna, Austria,2004, pp. 713-721.

[17]L. Sun, Q. Zheng, Y. Li, and R. Bhargava, "Understanding effects of wet compression on separated flow behavior in an axial compressor stage using CFD analysis," Journal of Turbomachinery, vol. 133, p. 031026, 2011.

[18]L. Sun, Q. Zheng, Y. Li, M. Luo, and R. K. Bhargava, "Numerical Simulation of a Complete Gas Turbine 
Engine With Wet Compression," Journal of Engineering for Gas Turbines and Power, vol. 135, p. 012002, 2013.

[19] A. White and A. Meacock, "An evaluation of the effects of water injection on compressor performance," in ASME Turbo Expo Atlanta, Georgia, June 16-19, 2003, collocated with the 2003 International Joint Power Generation Conference, 2003, pp. 181-189.

[20] T. Wang and J. R. Khan, "Overspray and Interstage Fog Cooling in Compressor Using Stage-Stacking Scheme: Part 1-Development of Theory and Algorithm," in ASME Turbo Expo 2008: Power for Land, Sea, and Air, Berlin, Germany June 9-13, 2008, pp. 99-109.

[21] T. Wang and J. R. Khan, "Overspray and Interstage Fog Cooling in Compressor Using Stage-Stacking Scheme: Part 2-Case Study," in ASME Turbo Expo 2008: Power for Land, Sea, and Air, Berlin, Germany June 9-13, 2008, pp. 111-121.

[22] R. K. Yadav and D. K. Reshmi Basak, "Review On Heat Transfer From Fins," in International Conference on Advanced Material Technologies (ICAMT), Visakhapatnam, India December 27-28, 2016.

[23] G. Montalvo-Catano and W. F. O’Brien, "Performance Modeling of a Power Generation Gas Turbine With Wet Compression," in ASME 2011 Turbo Expo: Turbine Technical Conference and Exposition, Vancouver, Canada June 6-10, 2011, pp. 665-674.

[24]S. O. Oyedepo and O. Kilanko, "Thermodynamic analysis of a gas turbine power plant modelled with an evaporative cooler," 2012. International Journal of Thermodynamic (IJOT) Vol.17 (No.1) pp. 14-20 2014 ISSN 1301-9724 / e-ISSN 2146-1511 doi: $10.5541 /$ ijot. 480

[25]C. Matz, G. Cataldi, W. Kappis, G. Mundinger, S. Bischoff, E. Helland, et al., "Prediction of Evaporative Effects Within the Blading of an Industrial Axial Compressor," Journal of Turbomachinery, vol. 132, p. 041013, 2010.

[26] W. M. Elwan, M. R. Shaalan, M. M. Nassief, and M. H. Gobran, "Computed Effect of Varying Tip Clearance and Axial Gap on Gas Turbine Stage Performance Part (I):(Steady Flow)," The Egyptian International Journal of Engineering Sciences \& Technology, vol. 20, pp. 68$74,2016$.

[27]Z. Mustafa, P. Pilidis, J. A. A. Teixeira, and K. A. Ahmad, "CFD aerodynamic investigation of air-water trajectories on rotor-stator blade of an axial compressor for online washing," in ASME Turbo Expo 2006: Power for Land, Sea, and Air, Bercelona, Spain May 8-11, 2006, pp. 1385-1394.

[28]M. Rahbar and H. Khaledi, "A study on fuel consumption at Siemens V94. 2 gas turbine considering different turbine control methods," in Thermal Power Plants (CTPP), 2011 Proceedings of the 3rd Conference, Tehraan,Iran ,October 18-19, 2011, pp. 16. ieeexplore.ieee.org/document/6576967

[29]E. Ulrichs and F. Joos, "Experimental investigations of the influence of waterdroplets in compressor cascades," in ASME Turbo Expo 2006: Power for Land, Bercelona, Spain May 8-11, Sea, and Air, 2006, pp. 221-230.

[30] G. D. m. Roointon pavri, "Gas Turbine emissions and control " p. 2, March 2001. GER 4211, GE power systems, Schenectady, New york, USA. https://stpowergen.gepower.com

[31] T. Nikolaidis, "Water ingestion effects on gas turbine engine performance," A phD Thesis published by Cranfield University, october 2008

[32]H.-s. HU, J.-x. ZHAO, J.-p. ZHONG, R.-w. JIANG, and M.-Z. YIN, "A new adjustment method of combustor outlet temperature field [J]," Journal of Aerospace Power, vol. 8, p. 004, 2007.

[33]H. Akimoto and H. Narita, "Distribution of SO2, NOx and $\mathrm{CO} 2$ emissions from fuel combustion and industrial activities in Asia with $1 \times 1$ resolution," Atmospheric Environment, vol. 28, pp. 213-225, 1994.

[34] M. Christodoulou, K. Moodie, W. Rattigan, and B. Ewan, "Safe operation of combined cycle gas turbine and gas engine systems using hydrogen rich fuels," in Gas Turbine Instrumentation, EVI-GTI and PIWG Joint Conference Berlin Germany, 27-29 Sept 2016, pp. 1-36.

[35]G. Bisio and F. Devia, "Interstage cooling in compressors [for gas turbines]," in Energy Conversion Engineering Conference, Honololu USA 1997. IECEC97., Proceedings of the $32^{\text {nd }}$ Intersociety, pp. 1592-1599.

[36] M. Komjáty, L. Főző, and R. Andoga, "Experimental identification of a small turbojet engine with variable exhaust nozzle," in Computational Intelligence and Informatics (CINTI), 2015 16th IEEE International Symposium, Budapest, Hungary, 19-21 Nov. 2015, pp. 65-69. ieeexplore.ieee.org/document/7382895/ 